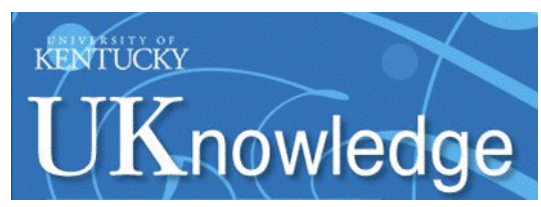

University of Kentucky

UKnowledge

$10-2015$

\title{
Decisions to Prosecute Battered Women's Homicide Cases: An Exploratory Study
}

\author{
Sarah N. Welling \\ University of Kentucky College of Law, swelling@uky.edu \\ Diane Follingstad \\ University of Kentucky, follingstad@uky.edu \\ M. Jill Rogers \\ Frances Jillian Priesmeyer \\ University of Kentucky, jpriesmeyer@gmail.com
}

Follow this and additional works at: https://uknowledge.uky.edu/law_facpub

Part of the Criminal Law Commons, and the Law and Gender Commons

Right click to open a feedback form in a new tab to let us know how this document benefits you.

\section{Repository Citation}

Welling, Sarah N.; Follingstad, Diane; Rogers, M. Jill; and Priesmeyer, Frances Jillian, "Decisions to Prosecute Battered Women's Homicide Cases: An Exploratory Study" (2015). Law Faculty Scholarly Articles. 588.

https://uknowledge.uky.edu/law_facpub/588

This Article is brought to you for free and open access by the Law Faculty Publications at UKnowledge. It has been accepted for inclusion in Law Faculty Scholarly Articles by an authorized administrator of UKnowledge. For more information, please contact UKnowledge@lsv.uky.edu. 
Decisions to Prosecute Battered Women's Homicide Cases: An Exploratory Study

Digital Object Identifier (DOI)

10.1007/s10896-015-9725-7

Notes/Citation Information

Diane R. Follingstad, M. Jill Rogers, Sarah N. Welling \& F. Jill Priesmeyer, Decisions to Prosecute Battered

Women's Homicide Cases: An Exploratory Study, 30 J. Fam. Violence 859 (2015). 


\title{
Decisions to Prosecute Battered Women's Homicide Cases: An Exploratory Study
}

\author{
Diane R. Follingstad $^{1}$ - M. Jill Rogers ${ }^{2} \cdot$ Sarah N. Welling ${ }^{3}$ - F. Jill Priesmeyer ${ }^{2}$
}

Published online: 5 May 2015

(C) Springer Science+Business Media New York 2015

\begin{abstract}
Discretionary decisions to prosecute cases in which a battered woman kills her partner were investigated using several research strategies and targeting a range of case elements. Law students presented with case elements reported they would consider legal elements over nonlegal (or "supplemental") elements when making a decision to prosecute. In contrast, law students assessed through an open-ended format as to important case factors for deciding to prosecute spontaneously generated high proportions of supplemental case elements compared with legal factors. Vignette comparisons of 42 case elements on participants' likelihood to prosecute identified salient factors including legal and supplemental variables. Themes from the open-ended responses are discussed, as well as the extent to which supplemental factors were more likely to be considered in prosecution decisions when assessed through different methodological strategies.
\end{abstract}

Keywords Prosecution decisions · Stereotypes - Battered women $\cdot$ Legal decision-making $\cdot$ Legal attitudes

Understanding how decisions are made to prosecute a battered woman who has killed her partner but claims self-defense is of utmost importance because of the variability in decisions for seemingly similar cases. Although these cases are complex, it is likely that societal ambivalence about battered women

Diane R. Follingstad

Follingstad@uky.edu

1 Department of Psychiatry, Medical College, University of Kentucky, 245 Fountain Court, Lexington, KY 40509, USA

2 Department of Educational, School, and Counseling Psychology, University of Kentucky, Lexington, KY, USA

3 College of Law, University of Kentucky, Lexington, KY, USA
(BW) and difficulty matching facts of their cases with historically derived self-defense criteria may influence decisions to prosecute a woman who has killed her partner (Gillespie 1989). Using self-report to determine whether decision makers believe their pre-existing attitudes and beliefs influence their decisions, especially legal decisions, has long been acknowledged as difficult to ascertain and has generally been discarded as a viable method. The following article explores methods for collecting data on case elements that may impact decisions to prosecute battered women charged with the homicide of their intimate partners. The authors first discuss the difficulties inherent in using self-defense as a justification for killing when the defendant is a battered woman followed by an analysis of the complexity involved in decisions to prosecute. Next, several methodologies are used to elicit responses of decision makers to such cases through 1) reactions to listed case factors; 2) spontaneously generated answers to an openended format following a brief case description; and 3) reactions to manipulated case factors in sets of vignettes. The results and discussion examine how supplemental variables, above and beyond legal criteria, appear to impact decisions to prosecute.

\section{Battered Women's Homicide Cases}

The judgments that culminate in a decision to prosecute in cases where a battered woman has killed a physically abusive partner hold obvious and frequently dire consequences for potential defendants. Despite the gravity of these decisions and the relatively unchecked power of the decision makers, little is known about factors influencing these processes. The divergent outcomes regarding prosecution (e.g., Pate 1994) for battered women's cases that seem markedly similar make prosecution decisions seem mysterious and difficult to predict. 
And, beyond the enormity of the stakes for these defendants (Radelet and Pierce 1985), the highly inconsistent outcomes (Goetting 1987; Pate 1994; Wilbanks 1983) raise concerns regarding potential miscarriages of justice.

Even if a battered woman is eventually acquitted after killing in self-defense (SD), just being prosecuted has serious consequences. A study of felony defendants (Cohen and Kyckelhahn 2010) in the 75 largest urban counties in the United States demonstrated that the literal act of charging a person with murder resulted in: $92 \%$ being detained in jail until case disposition; $47 \%$ being denied bail; exorbitant rates of bail; lengthy adjudication of cases; high conviction rates (81\%); and almost perfect certainty of being sentenced to prison if convicted or entering a plea bargain (98\%). Thus, simply entering the judicial system can have massive consequences for these women.

Because no jurisdiction has ever allowed battered women to introduce their battering history as an explanation, in and of itself, to justify killing their partner, information about the woman's history and the sequelae of battering (often summarized as Battered Woman Syndrome but more recently presented as Post-traumatic Stress Disorder (PTSD) - see Follingstad (2003)) has been allowed for consideration within a narrow legal context. Specifically, information as to how that traumatic experience might impact the perceptions and decisions battered women engage in that are relevant to a variety of legal standards (e.g., self-defense, provocation, duress, insanity, diminished capacity) has been allowed as pertinent evidence. For self-defense cases, battering history and psychological sequelae are typically introduced as evidence to bolster the claim that the woman reasonably believed she was in imminent danger, that is, her perceptions and actions fit within classic self-defense. Thus, it would be well within expectations that battered women's homicide cases would be viewed from the beginning through a lens of potential self-defense. In reality, however, battered women's homicide cases seem to result in widely discrepant decisions to prosecute, even when early data collection in a case suggests that SD seems a viable explanation for the killing. What is it about these cases that prosecution decisions are so varied? These cases are often complex and ambiguous in nature, representative of a serious societal violation, likely to possess emotional components, and reasonably vulnerable to preformed and stereotypic notions of the defendants. Of necessity, the person deciding whether to prosecute must simultaneously consider a defense to the crime at the same time they must consider whether the criteria for a crime were probably met (i.e., "probable cause"). Ambiguity abounds with the uncertainty as to whether the man (as the person killed) or the woman (as the recipient of battering) is the true victim. High emotionality is frequently exhibited on both sides, and long-standing stereotypes and myths regarding BW are easily resurrected and applied to these women defendants. Specifically, attitudes may be triggered toward the following aspects of battered women's cases: 1) claims of SD (Follingstad 1996; Follingstad 2003; Follingstad et al. 1996; Follingstad et al. 1989; Follingstad et al. 1997; Kahan and Braman 2008); 2) BW who kill (Blackman 1990; Jenkins and Davidson 1990; Russell and Melillo 2006; Schneider and Jordan 1978; Schuller et al. 1994); 3) BW as a group (Follingstad et al. 1988; Follingstad et al. 2001; Follingstad et al. 1990; Gillespie 1989); 4) women's roles (Gillespie 1989; Schneider and Jordan 1978); and 5) crime/criminals (Kalven 1969; Narby et al. 1993).

The obvious defense for many battered women's homicides is justifiable SD. However, a major difficulty in using this defense appears to be the criteria that must be met that may not reflect the conditions under which BW who kill often find it necessary to defend themselves (Gillespie 1989). A BW typically kills after a long history of repeated physical abuse that gradually shapes her expectations and beliefs about danger as well as her interpretations of interpersonal cues signaling violence. The judgment of a BW who kills, about whether she was in grave danger at the time of the killing and whether deadly force was necessary (both elements of SD law), may be impossible to establish without a nuanced understanding of her relational history and her subjective perceptions shaped by that history. Because a legal analysis of SD relies upon scrutiny of facts at the time of the killing, the woman's history is often not initially explored or considered relevant. Investigations of battered women's homicide cases leading to prosecution decisions rarely demonstrate a careful inquiry into her perceptions, reactions, and thought processes at the time of the killing and during preceding events (Gillespie 1989).

Another difficulty in defending women as acting in SD is the frequent mismatch of SD criteria historically developed on models of male combatants (Gillespie 1989) with BW's experiences. Different from dangerous male-to-male situations, violence in BW's relationships is often characterized by ongoing episodes without clear beginnings and endings that would better define parameters for when a person is in danger, e.g., the man's ongoing verbal threats to kill the woman greatly expand the time frame of dangerousness (Roberts 1996). A woman may defend herself when she perceives a lull in the violence or when the man appears temporarily unable to harm her, e.g., passed out from drugs or alcohol, because she knows the violence will soon resume its dangerous level and she will not be able to protect herself (Schuller et al. 2004). Technically, if women act upon their knowledge of cues that they know always signal the man will soon assault them, their actions are likely considered pre-emptive strikes rather than SD. And, by acting in anticipation of a deadly attack, e.g., her awareness of escalating threats, the woman likely has no injuries or evidence of assault to prove she was facing a dangerous episode. If a BW lives in a state that legislates that people 
have a "duty to retreat" if at all possible from dangerous situations, but the woman has never been able to escape the man's assaults, or she lacks transportation, or the man has issued a threat that he will kill her if she leaves, her historical experience may not be taken into account in a legal analysis of her ability to retreat. Size and strength differences may not be considered if a woman resorts to using a weapon, which may be viewed legally as a violation of the SD rule that a person's response to violence must match the level of violence directed at him/her rather than escalating the violence to a more dangerous level. Women's lack of knowledge as to what amount of force is required to disable a man who has demonstrated physical power over her may result in her using more serious force (e.g., more shots) than technically what would be considered "reasonable" SD between men combatants. And, when some women have responded to the man's violence historically by using physical force to protect themselves, this may be interpreted by the decision maker as both members of the couple being physically abusive, therefore she is not a "victim," and therefore she cannot justify her killing of him as protection from harm (Ewing and Aubrey 1987; Russell and Melillo 2006).

The difficulty mapping SD criteria onto cases involving BW, combined with society's ambivalent attitudes toward $\mathrm{BW}$, and the fact that the woman is usually the only witness to the events, have all likely contributed to inconsistent outcomes. Quasi-experimental studies manipulating SD elements, characteristics of the woman, or aspects of the case have begun to demonstrate that mock jurors can even be influenced by factors that are not pertinent to decisions of guilt/ innocence and that some of the unique perspectives of battered women are not understood by average jurors as having salient implications for SD (Braden-Maguire et al. 2005; Cheyne and Dennison 2005; Finkel et al. 1991; Follingstad et al. 1989; 1997; Terrance et al. 2000). Therefore, if those persons making prosecutorial decisions do not have such specialized knowledge regarding BW's experiences, these homicide cases appear especially vulnerable to being prosecuted. For example, some societal stereotypes which may negate an explanation of SD as a BW's response to an assault include: BW are masochistic and wish to be beaten (Kuhl 1984); BW create the problems for which they are physically abused, therefore deserving the abuse (Snell et al. 1964); women are irrational, emotional, and not logical (Gillespie 1989). (See Table 1 for stereotypes regarding battered women and their homicide cases upon which many of the case elements for this study were devised.)

Different from many homicides, a wider range of evidentiary components are often available in BW's homicide cases for interpretation in the decision to prosecute. Battered Women typically are the ones to call for help following the violent incident (Browne and Williams 1989), and therefore who killed the man is typically not an issue. Because of this, law enforcement can immediately observe the woman's initial reactions, note whether any injuries are present, witness an unmodified homicide scene, and question the woman - all data for addressing legal issues of SD and guilt/innocence specific to the killing incident. These cases also provide supplemental material potentially pertinent to the case in the form of historical information about the battering relationship if it is collected during the investigation. While this supplemental data may help support a claim of SD, it can also be dissected by decision makers who believe that, from specific pieces of data, they can ascertain the credibility of the woman's SD claim by determining whether the battering relationship was dangerous enough to justify her need to defend herself. There are no specific guidelines to know exactly what battering experiences would convince the person who is deciding whether or not to prosecute, but typically objective documentation (e.g., medical records, protective orders) or data establishing the physical battery as severe (e.g., man threatened woman with a gun in the past; threats to kill; serious injuries) seem to be required. And last, these cases like all criminal cases, possess extraneous elements that should not influence decisions to prosecute (e.g., characteristics of the woman and/or the man; external pressures to prosecute or not, demographic data, and presence of children), although a case can be made that BW as potential defendants are even more subject to stereotypes, biases, and other irrelevant factors. (See Table 2 for a detailed listing of specific elements for legal and supplemental categories of case elements.)

\section{Decisions to Prosecute}

Discrepancies among prosecutorial decisions for the full range of criminal charges, not just BW cases, led O'Neill (2004) to conclude that " ...[u]nderstanding why prosecutors select certain cases for prosecution and disregard others is one of the greatest enigmas of the criminal justice system" (p. 1439). Although a decision to prosecute supposedly rests upon a straightforward, rational appraisal of case evidence to determine the probable likelihood a suspect committed an act that meets the formal, legal definition of a crime, this description may greatly underestimate the process and types of information that end up influencing the final decision. Even with simpler criminal cases, deciding to prosecute requires initial identification of evidence followed by selective weighting and interpretation of the evidence. Along with determining an explanatory sequence or "story" that assigns an estimate of probability that a crime was committed (Pennington and Hastie 1992), the decision maker must match evidence to a specific type and level of crime (e.g., murder vs. manslaughter vs. reckless homicide) that often requires a nuanced assessment of situational and psychological variables involving inferences and attributions about intent, motive, and state of mind. 
Table 1 Stereotypes potentially affecting decisions to prosecute which provided the basis for case elements in the study

1. Women create the problems for which they are abused. ${ }^{\mathrm{P}}$

2. Woman should leave the relationship so that abuse does not escalate over time. ${ }^{\text {RET }}$

3. Women are masochistic and want to be hurt. S; REA

4. Women overreact (i.e., therefore the situation was misinterpreted as dangerous). ${ }^{\mathrm{S}}$

5. Women aren't rational or logical - why would she believe he would kill her this time? ${ }^{\text {REA }}$

6. The woman cannot start an argument and then expect nothing to happen. ${ }^{\mathrm{P}}$

7. Women should not resort to a weapon if the man is only using his hands and feet to attack her. ${ }^{\mathrm{E}}$

8. A verbal threat is not sufficient to justify killing, i.e., it is too vague as to when or whether it would happen. ${ }^{\mathrm{E} ; \mathrm{S}}$

9. The man's "cues" interpreted by the woman do not seem dangerous enough. ${ }^{\text {S; } \text { i; REA }}$

10. There is no reason the woman could not have escaped out of the situation. ${ }^{\text {RET }}$

11. She should have left the relationship a long time ago so this would not have happened. ${ }^{\text {RET }}$

12. There are no medical or police records, so she must be making it up. ${ }^{\text {S; REA }}$

13. The woman's interpretations of the man's behavior and dangerousness are illogical. ${ }^{\text {REA }}$

14. The woman's claim that she was still in a dangerous period from which she could not escape is not believable if the physical beating seemed to have stopped. ${ }^{\text {I }}$

15. Just because she couldn't escape before does not mean she could not have escaped this time. ${ }^{\text {RET }}$

16. The woman's view of her partner as omnipotent is not believable. ${ }^{\text {REA }}$

17. If the woman ever used physical force in return, either she can hold her own and did not need to kill him, or she is as much to blame as he is for the physical abuse. $^{\text {S; P; REA }}$

18. If the woman is not small of stature, then consideration of physical size/strength differences is negated. S; REA

19. The woman's claim that she continued to be fearful of the man after one shot or stab which led to more shots or stabs is unreasonable - another motive must be at work. D; E; REA

20. The woman's abuse experience does not seem to be severe enough to suggest fear of bodily harm or death, e.g., no prior life-threatening injuries. $\mathrm{S}$, REA

21. The woman was responsible for getting some type of external help to prevent all of this. ${ }^{\text {RET; REA }}$

22. The woman is likely a deficient character - either a weak character or undesirable one. ${ }^{\text {REA }}$

23. The woman should appear extremely upset and hysterical after a homicide; otherwise she seems to be a cold-blooded murderer. [Conversely, if she appears hysterical, she is an unreasonable, out-of-control person. $]^{\text {REA }}$

24. Any actions after the killing except calling police/ambulance are suspect. ${ }^{\text {REA }}$

25. Battered women have many other motives for killing the partner as a result of how they were treated, e.g., revenge, insurance, tired of the abuse, quicker way to get rid of the man than divorce. ${ }^{\text {REA }}$

26. If an argument proceeded this, the woman is responsible for provoking the physical incident that ended in her killing him. ${ }^{\mathrm{P}}$

27. A beating is not all that serious. ${ }^{\mathrm{S}}$

28. If they were not face-to-face when she shot/stabbed him, danger was not imminent. ${ }^{\mathrm{I}}$

29. If the woman acted impulsively, then she is not acting reasonably. ${ }^{\text {REA }}$

30. Because of the effects on her from the abuse, the woman cannot make a reasoned decision. ${ }^{\text {REA }}$

31. If she is the only witness to the killing, the woman is suspect. ${ }^{\text {REA }}$

32. The woman's reported fear is not a good enough reason to kill someone. ${ }^{\text {REA }}$

33. A man would not have interpreted the situation as the woman did. ${ }^{\text {REA }}$

Superscripts refer to the self-defense element that would be impacted if a person believes the statement. The elements are: ${ }^{S}$ seriousness of the physical danger, ${ }^{I}$ imminence of the danger, ${ }^{R E T}$ ability to retreat from the situation, ${ }^{P}$ freedom from provocation, ${ }^{E}$ equal force rule (i.e., cannot escalate), ${ }^{D}$ use only force necessary to disable attacker, and ${ }^{R E A}$ reasonableness of the person's perceptions and judgments in the situation

It is only in recent years that researchers have attempted to apply research models with prosecuting attorneys (PAs) to determine whether factors other than legal concepts influence their legal decisions. A small body of literature on the discretionary powers of PAs has accumulated since Shaver et al. (1975) expressed their concern at the lack of scientific scrutiny directed at PAs' decision-making. Unfortunately, these studies have chosen limited and concrete factors as predictors of prosecution rather than utilizing variables that would demonstrate the influence of less-conscious decision-making or preexisting stereotypes (Albonetti and Hepburn 1996). Thus, research studies have investigated the impact of gender, bail outcome, presence of witnesses, arrest at the scene, victimoffender relationship, a prior record, potential sentence length, an identifiable victim (Albonetti 1986), attorney type (Parrotta 2006), and district size, resource scarcity, and prioritization of cases (O’Neill 2004) on prosecution decisions. One study (Myers and Hagan 1979) concluded that decisions to 
Table 2 Coding categories of legal and supplemental variables with frequency of occurrence

Legal variables (243 responses)

Self defense elements (163 responses)

Serious harm was imminent* (84 responses)

Reasonableness of belief of danger* (32 responses)

Only enough force to disable* (14 responses)

Retreat if possible* (10 responses)

Not the one to provoke conflict* (6 responses)

Reciprocal amount of force to what received (2 responses)

Believability of guilt or innocence* (80 responses)

Cause of death

Possible motives

Her subsequent actions at the scene

Her subsequent reactions to man's death

Her claims of why killing occurred (from statement/talking with police)

Her interpretation of partner's actions at the time

Supplemental variables (396 responses)

Credibility of battering issues (211 responses)

Evidence/documentation of physical abuse historically* (45 responses)

Prior domestic violence calls to police* (20 responses)

Level of seriousness of past abuse* (frequency, duration, severity, injuries) (77 responses)

Evidence of prior protective disorders (3 responses)

Evidence that she engaged in actions to diminish abuse or leave the relationship* (28 responses)

Evidence of controlling/dominance in addition to physical abuse* (15 responses)

Predictability of his violence ( 0 responses)

Recency of battering and major episodes (4 responses)

General quality of relationship reported by others* (7 responses)

External threats by the man toward her family members/children/ friends (8 responses)

Extraneous supplemental factors (185 responses)

Characteristics of the woman* (129 responses)

Mental health issues* (44 responses)

Substance/alcohol use (10 responses)

Reputation* (33 responses)

Whether the woman was ever violent either generally or toward her partner* (34 responses)

Whether she protected the children from abuse ( 8 responses)

Physically disabled

Characteristics of the man (28 responses)

Mental health issues* (5 responses)

Substance/alcohol use (3 responses)

General violence by the man* (15 responses)

Positive reputation of man (4 responses)

Negative reputation of the man (not re: violence, e.g., affair)

(1 response)

Demographics (11 responses)

SES (4 responses)
Table 2 (continued)

Ethnicity (0 responses)

Marital status (0 responses)

Employment status* (4 responses)

Age (2 responses)

Number of children (1 response)

External sources of pressure (11 responses)

Community pressure (6 responses)

Media coverage ( 0 responses)

Man's family's opinion/preference regarding prosecution*

(2 responses)

Advocacy group involvement* (0 responses)

Lack of resources for woman in the past (1 response)

Legal considerations of the community, e.g., cost, caseload

(2 responses)

Impact on children (6 responses)

Children witnessed abuse to mother in past (2 responses)

Children would be placed in foster care/parentless if prosecuted

(2 responses)

Children also abused in past ( 2 responses)

*=Legal and Supplemental variables used on SCE scale

prosecute were based on the likelihood of being able to obtain a guilty verdict plus the perceived dangerousness of the defendant. However, Fairfax (2008) stated, what is often thought but not confirmed, that “...prosecutors just as often decide whether to charge based on factors other than the sufficiency of the evidence" (p. 734). This relatively private decision with its hidden process needs more empirical scrutiny to insure its accountability and to examine the types of nonevidentiary influences that may be part of that decision-making process.

Current research on information processing and social judgment suggests that individuals' perceptions of events can be selective, and that their interpretation of events (the organization of "facts" into meaningful patterns) may be heavily influenced by pre-existing decision rules, beliefs, attitudes, and emotional states. These pre-existing cognitive structures (labeled mental models, cognitive schemas, and heuristics; Myers 2002), constitute the lens through which people evaluate information, generate meanings, infer cause and effect, form judgments, and reach decisions, sometimes accomplished unconsciously (Gigerenzer et al. 1999; Goldstein and Gigerenzer 2002). Because they impose preexisting mental structures upon current situations, they also have the potential to contribute to various forms of bias, distortion and inaccuracy (Myers 2002). [Note: Basing judgments on pre-existing beliefs and schemas does not imply valence and can be experienced along a continuum of positive to negative skew.]

Although social scientists understand and expect that factors other than strictly legal ones could significantly affect decision-making in this realm, perhaps because lawyers are trained with an emphasis on rationality and legal specificity, attorneys may believe their decisions are much less influenced by any pre-existing schemas. However, persons can, at any time, be aware or unaware of the origin or content of a 
particular attitude or aware of the attitude and its source but not aware of its impact (Gawronski et al. 2006; Greenwald and Banaji 1995). Stereotypes constitute a subset of attitudes that have an influence on information processing when activated (Brewer 1996). There is also evidence that preformed schemas and mental models become increasingly influential for individuals' judgments in complex, uncertain, and ambiguous situations (Piperides et al. 2006). That description is easily applied to legal cases where conflicting evidence, gaps in evidence, irrelevant information, and criteria for decisions do not always match carefully constructed criteria for crimes and defenses.

If persons responsible for deciding whether to prosecute a case generally understand that their main task consists of establishing the probability that a crime was committed through matching case facts to specified elements of a crime or its defense, then they likely expect an objective, fair, and rational decision would be based on legal considerations. Any nonobjective, irrelevant, personalized, or biased factors influencing the decision matrix would be considered a violation of justice. Thus, it is expected that individuals presented with case elements to consider when deciding to prosecute will report they are much more likely to consider legal elements as opposed to case elements having an indirect or little relationship to legal criteria (henceforth called supplemental factors). However, without providing such structure that allows individuals to more clearly present their "ideal" and intended approach to cases, but rather requiring decision makers to spontaneously devise their own criteria was expected to show that they generate supplemental factors (i.e., idiosyncratic, personalized, and stereotypic elements) as part of their considerations along with socially desirable responses (i.e., legal criteria). Collecting respondents' spontaneous remarks using an unstructured approach has a long history in the form of projective assessment in that "They provide a more direct readout of motivational and emotional experiences than do self-reports that are filtered through analytic thought and various concepts of self and others" (pp. 698-699) (McClelland et al. 1989). This methodology has been used in nonlegal settings (e.g., Allen et al. 1988) and is beginning to be recognized as a productive technique when researching legal concepts if more spontaneous and unfiltered responses are desired (e.g., Smith 1991).

\section{Purpose of this Study and Hypotheses}

This exploratory study seeks to determine whether supplemental and extraneous factors are likely to be part of the decision-making process in addition to legal criteria in decisions to prosecute cases in which battered women killed their partners. This study also assesses whether reliance on supplemental and extraneous factors is more likely to occur when decisions to prosecute are measured through indirect methods, i.e., research strategies involving open-ended responses or vignette comparisons, than direct measurement of case factors. The following hypotheses were advanced and approached through different methodologies:

1. Presented with a face valid listing of legal and supplemental case elements potentially influencing decisions in a BW's homicide case, participants will report they are much more likely to consider legal elements when making decisions to prosecute as opposed to supplemental elements.

2. In response to instructions to spontaneously generate case elements of BW's homicide cases they would consider important for deciding to prosecute, participants will respond to this open-ended, unstructured format by producing supplemental factors (i.e., stereotypical and extraneous elements) in addition to legal factors.

3. Targeted case elements presented in vignettes, including stereotypical variables and unique problems inherent in BW's use of SD in homicide cases, will result in participants reporting a higher likelihood of prosecution when the vignette describes these elements when compared with contrasting vignettes, thus highlighting particular legal and supplemental variables that appear more salient for decisions to prosecute.

\section{Method}

\section{Participants}

Law students nearing the end of their course in Criminal Law were recruited as participants in this exploratory study to ensure similar knowledge regarding criminal law theory and statutes. Law students in different experiments did not differ as to their affinity toward a career as a prosecutor or whether they or someone close to them had been a victim of physical battering, prosecuted for a major or minor crime, or had a career in law enforcement, $\mathrm{F}(10,14)=0.30, p=$ n.s. In addition, across experiments, there were no demographic differences among the participants $F(10,92)=0.83, p=$ n.s., and an additional analysis by gender did not indicate differential responses to the various experimental conditions, $F(3,32)=$ $0.83, p=$ n.s.

Participants were 64 first year law students at a large public university in the Southeast. The participants ranged in age from 22 to 35 years old and the median age was 23 years old. Participants included 37 males $(57.8 \%$ ) and 18 females (28.1\%). Nine participants (14.1\%) did not answer this item. Of the 64 participants, 55 were Caucasian $(85.9 \%)$, five were African American (7.8 \%), two identified as Biracial (3.1\%), 
and one was Native American (1.6\%). One person chose not to disclose race $(1.6 \%)$. Fifty-nine of the participants had never been married (92.2\%), four were married (6.3\%), and one was divorced/separated (1.6\%). Thirty-one of the participants were from a small town $(48.4 \%), 22$ were from a suburban area $(34.4 \%)$, six were from a rural area $(9.4 \%)$, and five were from an urban area $(7.8 \%)$. Forty-three participants grew up in the Southeast $(67.2 \%), 16$ grew up in the Midwest (25.0\%), two grew up in the Northeast (3.1\%), one grew up in the Southwest (1.6\%), and two responded "not applicable" due to frequent moves (3.1\%). Thirty-three participants' family-of-origin income was over $\$ 100,000$ per year $(51.6 \%), 16$ had family incomes of $\$ 61000-\$ 100,000$ $(25.0 \%), 11$ had family incomes of $\$ 31,000-\$ 60,000$ $(17.2 \%)$, three had family incomes of $\$ 30,000$ or under (4.7\%), and one chose not to respond.

\section{Measures}

\section{Measurement of Legal and Supplemental Factors No} measures exist that examine individuals' reliance on specific case factors for making legal decisions. Therefore, based on prior research models, new instrumentation was developed for this study. Methodology I explicitly delineated legal and supplemental variables for BW's homicide cases to which participants reported the degree to they would take those factors into consideration when making decisions to prosecute. Methodology II required participants to spontaneously generate case elements they considered significant for decisions to prosecute. This method utilized an open-ended response technique (e.g., Allen et al. 1988) with the responses subsequently categorized by raters as to their legal or supplemental classification. Methodology III assessed the impact of hypothesized case factors on the likelihood to prosecute through comparisons of vignettes about BW's cases. Versions counter to each other of these case elements were presented to different participants - one version was hypothesized to decrease the likelihood of prosecution (e.g., the woman shot her husband only once when defending herself) while the other version was hypothesized to increase the likelihood of prosecution (e.g., the woman shot her husband four times).

\section{Categorization of Legal Versus Supplemental Elements}

Across measurement strategies, a priori conceptualization of the type of case factors likely to have legal relevance or influence decisions to prosecute BW's cases guided their inclusion and coding (See Table 2). Both legal standards and literature on battered women's legal cases (e.g., Gillespie 1989) were used to generate potential categories to be evaluated across the various measures. The broadest categorical division for factors potentially influencing decisions to prosecute is the use of legal elements (i.e., those rules of law regarding the alleged crime specified by statute or case law plus legal procedures expected to guide legal decision-making in particular cases) versus supplemental elements (i.e., those elements of cases that may indirectly inform decision-making that are not specific to the actual incident plus the range of irrelevant, potentially biasing, or stereotypical case factors). Legal and Supplemental elements are found in all three methodologies, but they are utilized differently for each exploratory study.

Applied to BW's homicide cases, the broad categories of Legal and Supplemental elements are each subdivided further into relevant subcategories. For the Legal component, SD is often the paramount consideration for deciding not to prosecute. Cases with specific descriptions meeting the six standard concepts of SD (i.e., perception of serious danger, perception of danger as imminent, reasonableness of the person's perceptions and actions, the person acting in SD did not initiate the physical incident, the use of defensive force was similar to that directed toward them and not more than that needed to stop the attack, and the person could not safely retreat) are case elements that would generally need to be met to fulfill criteria to establish SD. (See Table 1 for the stereotypes regarding BW and their cases that would appear to conflict with SD elements.) Thus, elements of SD are the first major Legal subcategory and separated from the second subcategory representing legal elements suggestive of Guilt/Innocence (e.g., motive; handling evidence; reporting promptly; the woman's emotional state following the incident).

For Supplemental elements, the first major subdivision consists of relevant case factors that they may indirectly raise or reduce credibility of major legal issues. Because SD elements apply strictly to the actual incident of the killing/injury, this subcategory (Credibility of Battering) encompasses characteristics of the woman's physical abuse history that decisionmakers might view as supporting or contradicting the woman's claims that her partner was dangerous at the time of the incident, whether the characteristics are pertinent, based on myths, or potentially misleading. Examples include: documentation of past injuries; prior calls to police; severity of the abuse; whether the woman followed through in obtaining protective orders or prosecuting her partner; whether the woman ever used physical force herself when attacked by the man; whether the man ever verbally threatened to kill her. Constituting the other major subcategory within Supplemental elements, is the Extraneous subscale representing elements which are more clearly irrelevant and often stereotypical that likely could still impinge upon decision-making, for example, victim and defendant characteristics, demographic variables, external sources of pressure, and the role of children. (See Table 2 for specific examples of Legal and Supplemental subcategories.)

\section{Methodologies}

Methodology I. Specific Case Elements Scale (SCE) This scale delineated 38 specific factors that would be potentially 
important for consideration when deciding whether to prosecute a BW's homicide case. Twelve items consisted of Selfdefense and Guilt/Innocence Legal elements, both scored as subscales as well as summed (SCELegal), and the other 26 variables consisted of Credibility of Battering and Extraneous Supplemental variables, both scored as subscales as well as summed (SCESupplemental) (See Table 2 for specific elements included on this scale). Participants responded to each case element using a 6-point Likert scale ( $1=\mathrm{I}$ absolutely would NOT consider this; $2=I$ most likely would NOT consider this; $3=$ I probably would NOT consider this; $4=$ I probably WOULD consider this; $5=$ I most likely WOULD consider this; and $6=\mathrm{I}$ absolutely WOULD consider this). Mean scores were calculated for all four subcategories and the two major categories.

Methodology II. Open-Ended Response Measure for Decisions to Prosecute (OE) This methodology used spontaneously generated responses of participants in reaction to a briefly described scenario as the data for analysis. Participants were instructed to imagine themselves as the prosecutor in a case in which a woman killed her husband and initial information collected in the case revealed that she claimed to be a battered woman. Participants were asked to spontaneously generate characteristics of these cases that they believed would influence them to decide whether the case should be prosecuted or not. One-half of participants were instructed to write ten characteristics that they believed would influence them to prosecute the case, after which they were instructed to repeat the task indicating factors that would suggest the case did not warrant prosecution. To control for order effects, the other half of the participants completing this measure performed the task in reverse order.

Two psychology graduate students were trained to code participants' responses based on descriptions of SD, Guilt/Innocence, Credibility of Battering, or Extraneous categories. The raters were highly similar in their coding for almost every categorization at the broadest level of Legal vs. Supplemental and for the major subdivisions within those categories $(\mathrm{kappa}=0.91)$. If raters disagreed as to the more specific subcategorizations, discussion with the primary researcher occurred until consensus was reached. Two types of participant responses that could not be resolved in this way resulted in the establishment of new subcategories.

Proportions of each of the four subcategories in relation to the total number of responses given by a participant were the scores used for analysis. For example, out of 20 possible openended responses, a participant could have indicated two legal SD responses $(2 / 20=0.10)$, six legal guilt/innocence responses $(6 / 20=0.30)$, eight supplemental responses as to credibility of battering $(8 / 20=0.40)$, and four extraneous responses $(4 / 20=0.20)$.
Methodology III. Experimentally Manipulated Factors Influencing Decisions to Prosecute (VIG) Forty-two factors that spanned the four subcategories of case elements were hypothesized to potentially influence the likelihood of prosecution based on literature from battered women's homicide cases, literature on battered women, and clinical/forensic experience (See Table 1). To test each factor, a pair of vignettes was devised in which one stated the factor being assessed while the other was the "control condition" for that factor. Thus, each pair of vignettes contained identical wording that varied only in the depiction of the "opposite" portrayal of the hypothesized factor (e.g., whether the man was shot in the front or the back). [Table 3 lists each manipulated factor and mean scores for each version.] Participants received only one version of a set, such that the group rating the likelihood of prosecution of one version could be compared with the group of participants who received the alternative version. Vignettes were distributed so that participants read some that might influence decisions to prosecute and some that would suggest the case might not warrant prosecution. They were also distributed so that participants read vignettes covering both Legal and Supplemental variables. After reading each vignette, participants rated the degree to which they thought the case should be prosecuted on a 6-point Likert scale $(1=$ Definitely NOT prosecute; $2=$ =Probably NOT prosecute; $3=$ Slightly think NOT prosecute; $4=$ Slightly think SHOULD prosecute; $5=$ Probably SHOULD prosecute; and $6=$ Definitely SHOULD prosecute). Mean scores were calculated for each version of the 42 vignettes.

Demographics Law students reported their age, gender, ethnicity, marital status, locale in which they were raised (i.e., urban, suburban, small town, rural), part of the country reared in, and family-of-origin income. As a gross determination of potential biases, participants were asked as to their potential interest in becoming a prosecutor and whether they had any exposure (i.e., with family, close friends, or self) to intimate partner physical violence, to being prosecuted for a crime, or having a career in law enforcement.

\section{Results}

\section{Methodology I. Comparison of Ratings of Specific Case Elements Impacting Likelihood to Prosecute}

For the law student sample $(N=22)$ that completed the SCE, a paired samples $t$-test was employed to compare their mean scores for intention to utilize legal elements of BW's homicide cases (SCELegal) when deciding to prosecute with their mean scores for intention to utilize supplemental elements (SCESupplemental). As predicted, law students significantly rated legal elements $(M=4.86)$ higher in terms of their 
Table 3 Univariate results of between group ratings on legal and supplemental variables manipulated in vignettes

\begin{tabular}{|c|c|c|c|c|}
\hline Legal and supplemental variables & Univariate $F$ & $\begin{array}{l}\text { Group } 1 \\
\text { mean }\end{array}$ & $\begin{array}{l}\text { Group } 2 \\
\text { mean }\end{array}$ & $\begin{array}{l}\text { Group } 3 \\
\text { mean }\end{array}$ \\
\hline Man shot in the front $\mathrm{a}$ vs. back $\mathrm{b}$ & $F(1,42)=0.007 \mathrm{~ns}$ & $4.35 \mathrm{a}$ & $4.32_{\mathrm{b}}$ & - \\
\hline Woman is a successful business woman ${ }_{\mathrm{a}}$ vs. homemaker ${ }_{\mathrm{b}}$ & $F(1,42)=2.177 \mathrm{~ns}$ & $4.10_{\mathrm{a}}$ & - & $3.50_{\mathrm{b}}$ \\
\hline Woman drinking during incident ${ }_{\mathrm{a}}$ vs. not drinking $\mathrm{b}_{\mathrm{b}}$ & $F(1,42)=27.324 * * * *$ & - & $4.91_{\mathrm{a}}$ & $3.32_{\mathrm{b}}$ \\
\hline Woman reports her statement to police as accurate ${ }_{a}$ vs. inaccurate ${ }_{b}$ & $F(1,42)=15.873 * * * *$ & $5.00_{\mathrm{a}}$ & $3.64_{b}$ & - \\
\hline No history of medical injuries $\mathrm{a}_{\mathrm{a}} \mathrm{vs}$. history of injuries from abuse $\mathrm{b}_{\mathrm{b}}$ & $F(1,42)=58.443 * * * *$ & $4.90_{\mathrm{a}}$ & - & $2.50_{\mathrm{b}}$ \\
\hline $\begin{array}{l}\text { Woman shoots immediately after severe threat }{ }_{a} \text { vs. man falls asleep after } \\
\text { severe threat and woman shoots while man sleeping } \mathrm{b}_{\mathrm{b}}\end{array}$ & $F(1,42)=50.609 * * * *$ & - & $2.57 \mathrm{a}$ & $4.86_{\mathrm{b}}$ \\
\hline Crime scene as described by woman ${ }_{a}$ vs. woman changed crime scene $_{b}$ & $F(1,42)=6.767 * *$ & $3.40_{\mathrm{a}}$ & $4.27 \mathrm{~b}$ & - \\
\hline Man's behavior unique when she shot him ${ }_{a}$ vs. predictive as signaling abuse $_{b}$ & $F(1,42)=2.391 \mathrm{~ns}$ & $4.35 \mathrm{a}$ & - & $3.77_{\mathrm{b}}$ \\
\hline Ex-wife reports no physical abuse ${ }_{a}$ vs. she reports similar battering $g_{b}$ & $F(1,42)=10.012 * *$ & - & $4.38_{\mathrm{a}}$ & $3.14_{b}$ \\
\hline Woman did not think to run out ${ }_{a}$ vs. did not run due to small children ${ }_{b}$ & $F(1,42)=16.798^{* * * *}$ & $3.95 \mathrm{a}$ & $2.50_{\mathrm{b}}$ & - \\
\hline No injuries on woman $a$ vs. injuries found on her at the time $e_{b}$ & $F(1,42)=35.399 * * * *$ & $4.90_{\mathrm{a}}$ & - & $2.59 \mathrm{~b}$ \\
\hline Boyfriend as victim $\mathrm{a}$ vs. husband as victim $\mathrm{b}$ & $F(1,42)=3.864 *$ & - & $3.62_{\mathrm{a}}$ & $4.32_{\mathrm{b}}$ \\
\hline Neighbors report hearing nothing $g_{a} v s$. hearing an argument before shooting $b_{b}$ & $F(1,42)=0.245 \mathrm{~ns}$ & $4.60_{\mathrm{a}}$ & $4.46_{\mathrm{b}}$ & - \\
\hline Man has a mental condition $a$ vs. man has no mental condition ${ }_{b}$ & $F(1,42)=4.991^{*}$ & $4.00_{\mathrm{a}}$ & - & $4.59 \mathrm{~b}$ \\
\hline Man's family wants prosecution of woman $a$ vs. does not want her charged ${ }_{b}$ & $F(1,42)=6.816^{*}$ & - & $3.67 \mathrm{a}$ & $2.73_{\mathrm{b}}$ \\
\hline Woman fired four shots $\mathrm{a}_{\mathrm{a}}$ vs. one shot $\mathrm{b}_{\mathrm{b}}$ & $F(1,42)=9.235^{* *}$ & $4.95 \mathrm{a}$ & $4.00_{\mathrm{b}}$ & - \\
\hline Woman is overweight ${ }_{\mathrm{a}}$ vs. small $_{\mathrm{b}}$ & $F(1,42)=8.029 * *$ & $4.30_{\mathrm{a}}$ & - & $3.00_{\mathrm{b}}$ \\
\hline Woman has a good reputation $a$ vs. not liked in community ${ }_{b}$ & $F(1,42)=18.334 * * * *$ & - & $3.34_{\mathrm{a}}$ & $4.59 \mathrm{~b}$ \\
\hline History of calls by her to police $\mathrm{a}_{\mathrm{a}}$ vs. no history of calls to police $\mathrm{b}_{\mathrm{b}}$ & $F(1,42)=31.362 * * * *$ & $2.65_{\mathrm{a}}$ & $4.55_{\mathrm{b}}$ & - \\
\hline Woman feared man still alive after shooting ${ }_{a}$ vs. knowing he was dead ${ }_{b}$ & $F(1,42)=5.649 *$ & $3.95 \mathrm{a}$ & - & $3.00_{\mathrm{b}}$ \\
\hline Inaccurately thought bulge was gun ${ }_{a}$ vs. accurately thought bulge was gun ${ }_{b}$ & $F(1,42)=32.464 * * * *$ & - & $4.76_{\mathrm{a}}$ & $2.73_{\mathrm{b}}$ \\
\hline Woman does not have a mental disorder $\mathrm{a}$ vs. woman has mental disorder $\mathrm{b}_{\mathrm{b}}$ & $F(1,42)=3.183 \mathrm{~ns}$ & $4.60_{\mathrm{a}}$ & $3.86_{\mathrm{b}}$ & - \\
\hline Uncertain why she shot four times $a_{a}$ vs. claimed fear influenced more shots $b$ & $F(1,42)=0.286 \mathrm{~ns}$ & $4.30_{\mathrm{a}}$ & - & $4.09 \mathrm{~b}$ \\
\hline Advocacy group became involved in case ${ }_{\mathrm{a}}$ vs. no advocacy involvement $\mathrm{b}_{\mathrm{b}}$ & $F(1,42)=8.854^{* *}$ & - & $3.38_{\mathrm{a}}$ & $4.36_{\mathrm{b}}$ \\
\hline Neighbor reported abuse lasting for 10 years ${ }_{a}$ vs. 10 months $_{b}$ & $F(1,42)=0.076 \mathrm{~ns}$ & $2.55_{\mathrm{a}}$ & $2.46_{\mathrm{b}}$ & - \\
\hline Never able to escape by running ${ }_{a}$ vs. prior success but not able to this time $e_{b}$ & $F(1,42)=0.208 \mathrm{~ns}$ & $3.95 \mathrm{a}$ & - & $4.09 \mathrm{~b}$ \\
\hline Man used hands and feet to abuse $\mathrm{a}_{\mathrm{a}}$ vs. history of putting gun to her head $\mathrm{b}_{\mathrm{b}}$ & $F(1,42)=1.336 \mathrm{~ns}$ & - & $3.14_{\mathrm{a}}$ & $2.72_{\mathrm{b}}$ \\
\hline Woman not diagnosed with $\mathrm{PTSD}_{\mathrm{a}}$ vs. woman diagnosed with $\mathrm{PTSD}_{\mathrm{b}}$ & $F(1,42)=35.845^{* * * *}$ & $4.45_{\mathrm{a}}$ & $2.55_{\mathrm{b}}$ & - \\
\hline Man's signal for abuse seems vague and not threatening $\mathrm{a}_{\mathrm{a}}$ vs. threatening $\mathrm{a}_{\mathrm{a}}$ & $F(1,42)=15.457 * * * *$ & $4.50_{\mathrm{a}}$ & - & $3.00_{\mathrm{b}}$ \\
\hline Calls to police on man only $y_{a}$ vs. calls on woman as well as $\operatorname{man}_{b}$ & $F(1,42)=58.058 * * * *$ & - & $2.71_{\mathrm{a}}$ & $4.77_{\mathrm{b}}$ \\
\hline Reputation of man as generally violent $\mathrm{a}_{\mathrm{a}}$ vs. no reputation of violence $\mathrm{b}_{\mathrm{b}}$ & $F(1,42)=6.587 *$ & $3.30_{\mathrm{a}}$ & $4.18_{\mathrm{b}}$ & - \\
\hline Last major abuse incident occurred within last 2 weeks $_{\mathrm{a}}$ vs. 3 years $\mathrm{ago}_{\mathrm{b}}$ & $F(1,42)=11.665^{* * *}$ & $3.20_{\mathrm{a}}$ & - & $4.41_{\mathrm{b}}$ \\
\hline No statements by woman of fearing man $_{a}$ vs. spontaneous statement of fear ${ }_{b}$ & $F(1,42)=2.795 \mathrm{~ns}$ & - & $4.52_{\mathrm{a}}$ & $4.00_{\mathrm{b}}$ \\
\hline Woman rumored to be having affair $_{\mathrm{a}}$ vs. woman thought to be faithful $\mathrm{b}_{\mathrm{b}}$ & $F(1,42)=15.776^{* * * *}$ & $4.95 \mathrm{a}$ & $3.77_{\mathrm{b}}$ & - \\
\hline Woman with African American name ${ }_{a}$ vs. Caucasian name $e_{b}$ & $F(1,42)=0.939 \mathrm{~ns}$ & $4.40_{\mathrm{a}}$ & - & $4.09_{\mathrm{b}}$ \\
\hline Woman was vague but claimed self-defense ${ }_{a}$ vs. claimed as accident $t_{b}$ & $F(1,42)=7.384^{* *}$ & - & $3.57 \mathrm{a}$ & $4.55_{\mathrm{b}}$ \\
\hline Historically, physical abuse plus verbal threats to kill $\mathrm{a}_{\mathrm{a}}$ vs. physical abuse only $\mathrm{y}_{\mathrm{b}}$ & $F(1,42)=0.508 \mathrm{~ns}$ & $3.35_{\mathrm{a}}$ & $3.59_{\mathrm{b}}$ & - \\
\hline Following incident, woman was hysterical ${ }_{\mathrm{a}}$ vs. woman was calm and quiet $_{\mathrm{b}}$ & $F(1,42)=31.641 * * * *$ & $2.95 \mathrm{a}$ & - & $4.82_{\mathrm{b}}$ \\
\hline Woman with inconsistent blue collar work history ${ }_{a}$ vs. successful business owner & $F(1,42)=0.433 \mathrm{~ns}$ & - & $4.05 \mathrm{a}$ & $4.23_{\mathrm{b}}$ \\
\hline Delay in calling 911 after shooting $\mathrm{a}_{\mathrm{a}}$ vs. immediately calling $911_{\mathrm{b}}$ & $F(1,42)=26.485^{* * * *}$ & $4.80_{\mathrm{a}}$ & $3.14_{b}$ & - \\
\hline Man's family claimed she threatened to kill him once ${ }_{a}$ vs. no threats known $_{b}$ & $F(1,42)=0.812 \mathrm{~ns}$ & $5.00_{\mathrm{a}}$ & - & $4.73_{\mathrm{b}}$ \\
\hline $\begin{array}{l}\text { Woman was able to clearly delineate what caused fear }{ }_{a} \text { vs. unable to clearly } \\
\text { delineate cause of fear }{ }_{b}\end{array}$ & $F(1,42)=21.047 * * * *$ & - & $3.43_{\mathrm{a}}$ & $4.82_{\mathrm{b}}$ \\
\hline
\end{tabular}

Group 1 and 2 MANOVA: $F(14,27)=6.407, p=.0001$. Group 1 and 3 MANOVA: $F(14,27)=11.459, p=.0001$. Group 2 and 3 MANOVA: $F(14,28)=$ $28, p=.0001$

Subscripts ${ }_{\mathrm{a}}$ and $\mathrm{b}_{\mathrm{b}}$ indicate which group mean corresponds with each version of the manipulated variable Significance is indicated as follows: ${ }^{* * * *} p \geq .0001 ; * * * p \geq .001 ; * * p \geq .01 ;{ }^{*} p \geq .05 ;$ ns not significant

Mean ratings based on the following response categories: $1=$ Definitely NOT prosecute, $2=$ Probably NOT prosecute, $3=$ Slightly think NOT prosecute, $4=$ Slightly think SHOULD prosecute, $5=$ Probably SHOULD prosecute, $6=$ Definitely SHOULD prosecute 
likelihood of considering those factors while making prosecution decisions than the supplemental elements $(M=4.08)$, $t(20)=8.36, p>0.0001$. Thus, participants rated their likelihood of utilizing SCELegal elements in their decisionmaking as "I most likely would consider this" as contrasted with the likelihood of "I probably would consider this" that they used for rating the SCESupplemental elements.

As expected, those completing the SCE rated their likelihood of considering legal self-defense elements $(M=5.79$ out of 6.00) significantly higher than legal elements relating to general guilt/innocence elements $(M=4.95), t(20)=$ $6.02, p>0.0001$. These scores indicated that the law students almost unanimously predicted that they would "absolutely" consider SD elements, while they still indicated a strong likelihood (i.e., "most likely") to consider Guilt/Innocence elements.

Law students' ratings on the SCE of their likely consideration of Credibility of Battering case elements $(M=$ 4.86) compared with Extraneous supplemental elements (e.g., characteristics of the woman/man; demographics) $(M=3.44)$ produced ratings in the expected direction. A paired samples $t$-test indicated a greater likelihood that participants would consider Credibility of Battering elements than they would consider Extraneous elements, $t(20)=12.83, p>0.0001$. Pertaining to battering history, the highest ratings were for variables related to the types of "proof "arising from the battering history that law students believe would bolster the woman's claim of the man's dangerousness: a) whether the woman required medical care due to battering in the past $(M=5.19)$; b) whether the woman had reported the man's physical abuse to the police $(M=5.14)$; $\mathrm{c})$ whether severe domination and control by the man accompanied the physical abuse $(M=$ $5.14)$; d) whether the woman had a history of mental illness $(M=4.81)$; e) whether the physical abuse had consisted of serious violence rather than milder forms $(M=5.19)$; f) whether the woman has been diagnosed with post-traumatic stress disorder from the abuse $(M=4.76)$; and g) whether the man had specifically threatened to kill her if she left him $(M=4.95)$. Interestingly, participants were also very likely to consider "whether the man had called the police complaining of physical force by the woman $(M=5.62)$, although it is expected that this would work to negate her claim of self-defense.

In contrast, the significant Extraneous elements were rated by participants in the lower half of the response range which indicated participants were not likely to consider those case elements. These included: a) the community's reaction to the case $(M=3.24)$; b) the reputation of the defense attorney $(M=2.57)$; c) whether local advocacy groups were involved in the woman's case $(M=2.05)$; d) the preferences of the man's family as to whether the woman should be prosecuted $(M=2.90)$; e) personal characteristics of the woman $(M=2.67)$; and f) whether or not the woman knew how to use guns $(M=2.76)$.

\section{Methodology II: Comparison of Open-ended Responses of Case Elements Impacting Likelihood to Prosecute}

The spontaneously generated responses of 41 law students to the OE measure were coded as representing the four subcategories of responses and standardized by calculating proportions of those responses, in comparison to the total number generated by each person. Analyses were conducted to determine whether first orienting participants to generate elements that would influence them to prosecute and second to generate elements inclined to influence them not to prosecute would produce different responses than the reverse order. A between groups $t$-test did not result in significantly different proportions of Legal versus Supplemental elements generated, $F(1$, 41) $=0.71, p=$ n.s.

The coding of the responses in the OE condition did not include any valence or "direction" of the responses, but only resulted in a coding of the subcategory to which each response belonged. Therefore, a second analysis compared the proportion of Legal responses for the condition in which participants were instructed to state case elements that would lead them "to prosecute" vs. the condition that would lead them "not to prosecute." Using paired sample $t$-tests for this comparison resulted in no significant differences, $t(42)=-0.64, p=$ n.s.

Because neither of the two potentially confounding conditions was related to the production of responses, data from both $\mathrm{OE}$ conditions were collapsed. Using a paired samples $t$-test to compare the proportion of Legal and Supplemental spontaneously generated responses resulted in a highly significant difference, $t(42)=-4.21, p>0.0001$. Participants produced almost two times as many Supplemental responses (proportion mean $=0.61$; total number of responses $=396$ ) as Legal responses (proportion mean $=0.39$; total number of responses $=243$ ).

The proportions of generated responses in the subcategories for Supplemental elements (i.e., Credibility of Battering History and Extraneous) were negatively correlated, $r(42)=-0.37, p>0.0001$, such that the more participants produced responses considering credibility of the battering, the less likely they were to generate extraneous elements, although the proportions of these two subcategories were not significantly different, $t(42)=1.16, p=\mathrm{n}$.s. It is important to note that, overall, $28 \%$ of the open-ended responses pertained to the Extraneous subcategory consisting of irrelevant and potentially biasing elements.

When participants generated case elements relevant to Credibility of Battering, the following issues were raised most often: the level of seriousness of past abuse; historical evidence or documentation of the physical abuse; evidence that the woman engaged in actions to diminish the abuse or leave 
the relationship; and evidence of prior reports of the abuse to the police by the woman. Within Extraneous factors, the following were raised most often: the woman's general reputation; whether the woman was ever violent toward her partner or anyone else; whether the man was generally violent; whether the woman used alcohol or drugs; the woman's mental health; and how the community was reacting to the case. (See Table 2 for frequencies for individual topics within all subcategories.)

\section{Methodology III: Comparison of Vignette Ratings of Case Elements Impacting Likelihood to Prosecute}

The three groups of law students reading different versions of the vignettes were compared on their general tendency toward prosecution. A one-way ANOVA found no differences in ratings, $F(2,61)=2.48, p=$ n.s.

Three separate MANOVAs were conducted to compare ratings for all 42 sets of vignettes. Specifically, the ratings of the 14 sets distributed to the first and second group, the ratings of the 14 sets distributed to the first and third groups, and the ratings of the 14 sets distributed to the second and third groups were the dependent variables for each MANOVA. The overall MANOVA was significant for all three analyses - Vignette Set $1(F(14,27)=6.41, p>0.0001)$; Vignette Set $2(F(14,27)=$ $11.46, p>0.0001)$; and Vignette Set $3(F(14,27)=19.26$, $p>0.0001)$. Subsequent univariate analyses $(p<0.05)$ demonstrated that two-thirds of the vignette pairs (i.e., 28 out of 42 sets) yielded significant differences in ratings of likelihood to prosecute (i.e., nine vignettes significantly different for Vignette Set 1; eight vignettes significantly different for Vignette Set 2; eleven vignettes significantly different for Vignette Set 3).

Of the 13 vignettes manipulating elements of SD, eight (62\%) produced significantly different ratings as to the likelihood of prosecution (See Table 3). Participants were more likely to prosecute if: 1) after a threat to kill, the man fell asleep and the woman shot him compared with shooting him immediately; 2) the woman did not retreat from the situation because she "did not think of it" vs. due to having small children in the home; 3) there were no apparent injuries evident on the woman at the time vs. presence of injuries; 4) the man was shot four times vs. shot only once; 5) the woman ran out of the house after the shooting knowing the man was dead so police would know where to come vs. running out of the house thinking the man was still alive and in fear of him; 6) the signal that the man was going to beat her was vague and ambiguous vs. the signal was obviously threatening; 7) the woman was vague but claimed the shooting was an accident vs. being vague but claiming self-defense; and 8) the woman could not explain clearly to the police what caused her fear vs. the woman being able to clearly delineate what caused her fear.
All four of the vignettes representing general guilt/ innocence factors of the cases produced different ratings. Participants were much more likely to rate vignettes as ones they would prosecute if: 1) the woman told her attorney that the written statement that the police had was her own and that it was accurate vs. the woman reported problems with the statement and said it was inaccurate; 2) the woman cleaned up the crime scene before the police came by vs. the crime scene viewed by the police was as the woman described it; 3 ) the woman misperceived a bulge in the man's pocket as a gun vs. the woman accurately perceived the bulge as a gun; and 4) there was an hour delay between the shooting and the woman calling 911 vs. there was no delay.

Ten of the vignettes manipulated factors regarding the credibility of a history of physical abuse, and six (60\%) of them were rated differently by participants. Law students were significantly more likely to prosecute if: 1) the woman had no medical history to corroborate injuries resulting from abuse vs. a documented medical history of injuries; 2) the deceased man's $e x$-wife reported she had not been physically abused by him vs. his ex-wife reported similar physical abuse; 3 ) there were no calls to police made by the woman regarding prior incidents of physical abuse by her partner vs. there was a record of her calling police about his violence; 4) an evaluation of the woman resulted in no diagnosis of PTSD from the physical abuse vs. the evaluation stated that she did have PTSD; 5) the woman had used some physical force herself toward the man vs. there was only unilateral violence by the man; and 6) the last major physical incident had occurred 3 years ago vs. taking place 2 weeks prior.

Extraneous elements comprised the manipulated factors in 15 vignettes, and $10(67 \%)$ of them produced significant differences between the two versions. Prosecution was much more likely to occur if: 1) the woman had been drinking a significant amount at the time vs. the woman had not been drinking at all; 2) the victim was the woman's husband vs. the victim was her boyfriend; 3 ) the man did not have any type of mental condition vs. the man had a history of mental disorder; 4) the dead man's family wanted the woman to be prosecuted for the death vs. the dead man's family did not want her to be prosecuted; 5) the woman was significantly overweight vs. the woman was very small; 6) the woman was not well liked in the community vs. the woman generally had a good reputation; 7) there was no involvement by any advocacy groups regarding the woman's case vs. there was active involvement by an advocacy group; 8 ) the man had no reputation for being generally violent in the community vs. the man had a reputation for violence; 9) the woman was rumored to be having an affair vs. the woman was thought to be a faithful wife; and 10) the woman was calm and quiet after the killing vs. the woman was hysterical.

Of interest are those SD elements that did not demonstrate significant differences even though they were predicted to 
influence decisions to prosecute. Specifically, the following scenario sets did not result in different ratings due to the manipulated variable: whether the woman specifically claimed to be afraid of the man vs. not stating such when talking with the police; whether the man was shot in the front vs. the back; whether the cue that the woman reported made her believe she was in danger was unique to the incident in which the man was killed vs. a familiar cue for battering she had experienced before; whether the woman explained she shot the man repeatedly out of fear vs. the woman having difficulty remembering why she shot repeatedly; and whether the woman reported never being able to escape from battering episodes in the past vs. often being able to escape in the past, but not that night.

\section{Discussion}

As predicted, different methods assessing whether particular case factors would influence decisions to prosecute battered women's homicide cases did result in apparent disparities. When presented with predesignated specific case elements, participants subjectively and deliberately reported their intention to more likely consider legal (i.e., self-defense and guilt/ innocence elements) over supplemental variables, and especially over extraneous variables. When spontaneously devising their own criteria with no lists or structure to guide them, participants generated many more supplemental factors to be considered in battered women's homicide cases than legal factors. When responding to hypothesized factors in vignettes that were expected to influence decisions to prosecute battered women's cases, participants very often were inclined to prosecute compared with the control vignettes. What makes these findings noteworthy is the extensive use of supplemental variables by the participants, especially when they were extraneous to BW's cases or salient for decision-making when methodologies were more indirect but not considered for decisionmaking when assessed directly, i.e., on a list of potential case variables. Most of the extraneous variables used or generated in this project are those that should not be part of a decision to prosecute, so their emergence when the data were collected indirectly (i.e., through open-ended responses or through vignette ratings) is somewhat alarming. This study cannot demonstrate how the combination of factors that a person might consider would result in a final decision, but based on the potential of many of these variables for tipping the balance toward prosecution when other aspects of a case might suggest a case should not be prosecuted is of concern.

Because two of the methodologies deliberately included case elements designed to reflect stereotypical thinking about battered women, the spontaneously generated case elements in the third, and least directive, methodology were of special interest. Would individuals with some legal training who were told to consider themselves in the role of a prosecutor produce responses that were strictly legal in nature and not reminiscent of myths and stereotypes about battered women? With over one-fourth of these responses codified as Extraneous variables, even taking into account those comments focused on the mental health of the man or woman, the range of nonessential, potentially biasing, and even blatantly worrisome elements that were extemporaneously injected for consideration in a prosecution decision were troublesome.

This research study cannot and does not assert that the extraneous factors arose from unconscious processes, but rather that their presence is noteworthy for the potential influence they might have, whether unconscious or not. The research showing that individuals, upon recognizing that they are relying on stereotypic information, may or may not be able to control the response that incorporates the stereotype (Banaji and Hardin 1996), illustrates what may be of more concern for decisions to prosecute in these cases when the activation of stereotypes occurs. However, because Devine (1989) demonstrates that the emergence of a stereotype may not always be linked with prejudice, such that one could know societal stereotypes but not endorse them or accept them, further research is needed to answer whether knowing stereotypes about BW actually impacts prosecution decisions or whether they only influence individuals who believe the stereotypes to be accurate across all $\mathrm{BW}$.

\section{Decision-making when Factors are Specifically Delineated}

In line with the expected outcome, participants making judgments about a designated list of specific case elements for BW cases for consideration when making decisions to prosecute produced ratings that linearly demonstrated their subjective and cognizant intent to 1) most definitely utilize legal selfdefense elements, 2) then to rely on legal elements assessing guilt/innocence, and 3) finally to "probably consider" aspects of the woman's history of being battered. Their ratings demonstrated that they would not likely consider extraneous supplemental elements.

It may be encouraging to note that the woman's history of battering would at least be given "probable" consideration if it were known at the time a decision to prosecute was made, even though a nuanced understanding of her relational history and her subjective perceptions shaped by that history may require much more in-depth investigation before a decision was made. Unfortunately, a woman's history of battering often only comes to light through a defense attorney raising this information and often regrettably after a decision to prosecute has been made. Even though some might be encouraged to think that legal decision makers would want to know about battered women's unfortunate histories and the impact of that information on the women's mental state and behavior, we do not know if this scrutiny is necessarily an empathic concern. The significant vignette factors pertaining to a woman's 
battering history seemed to suggest that unless a battered woman had good documentation of a) recent and b) severe mistreatment resulting in c) serious mental consequences (PTSD), she was going to be prosecuted. And, if she had ever used physical force to defend herself, she would most definitely be prosecuted. The only exception to the participants' dismissal of extraneous supplemental elements as factors they would consider was the woman's history of mental illness, which could have relevance for criminal responsibility. For all other factors in the extraneous category, however, participants were quite consistent in "not considering" all other extraneous case elements.

\section{More Indirect Assessment of Decisions to Prosecute}

Which case elements are given priority for consideration shifts fairly dramatically when decision makers respond to openended inquiry by generating factors they consider important for decisions to prosecute these cases. The second hypothesis, that indirect assessment would result in production of supplemental factors in addition to legal factors to consider when deciding to prosecute or not, was supported by the finding that two-thirds of participants' responses were focused on the credibility of the woman's battering history and extraneous case elements. The significance of the proliferation of supplemental elements is that even these relatively sophisticated participants produced issues for prosecution decisions that demonstrate stereotyping, requirements for these women's defense that would not be generally compelled for any homicide case, and factors that absolutely should not be considered for such a decision. Although it is unknown how much weight a participant would give to extraneous case elements compared with the rest of his/her generated answers, even lesser considerations or irrelevant or biasing elements could tip the balance from a decision maker being less willing to prosecute toward a willingness to prosecute.

The supplemental factors that were spontaneously generated from the open-ended response format resulted in several prominent themes. The first reflected the participants' concern that the woman had stayed in an abusive relationship. To avoid prosecution, she should have engaged in actions to fix the relationship or she should have left it; if the options she tried did not work, she was still a sympathetic figure and less likely to be prosecuted. If she did not try, especially if she was perceived as having resources (e.g., a job, being educated, support from others, her own income), then prosecuting her was a more likely option. This orientation is perilous for the woman's likelihood of ending up in the justice system even if she acted in self-defense, and it demonstrates misunderstanding of severe battering cases in which women are usually still present because of the man's repeated threats to kill her (or their child or a family member) should she try to leave. Even if threats were not present, her successful coping while in a very difficult relationship would be punished based on the externally imposed value that one is never allowed to remain in a relationship where physical force exists.

A second theme elicited from the spontaneous comments was the expectation that the woman must be an upstanding person in every way to reduce the likelihood of prosecution. Any deviation rendered her liable for prosecution (e.g., infidelity, not believing in God, using alcohol or drugs, any prior use of physical force, any prior record, her behavior provoking violence from her husband, not being from a prominent family, multiple marriages that implied she married men solely for money or status). What is not considered in this morallyoriented viewpoint that only "good" people are allowed to defend themselves is the potential impact of the abusive relationship on the woman's functioning over time. A woman may have tried to physically defend herself by using physical force herself. She might have turned to substances to relieve anxiety resulting from living with the threat of being beaten. Or, she may actually have problems which have no bearing on whether she needed to defend herself when she killed the man.

The general reputation of the husband in the community was the third theme. When decision makers suggested that information about whether the abusing husband was a "bad guy" would be important for their prosecution decision, the woman was less likely to be prosecuted (e.g., he was a convicted felon or habitual criminal; he was a wealthy man taking advantage of a poor woman; the man's abuse of her included sexual abuse). However, in what seems like an unfair assessment, she was more likely to be prosecuted if the man she killed was a prominent person in the community.

The role of children was an additional theme, but introducing children as a factor in prosecutions decisions could work either for or against a BW. The woman must not have endangered the children through her self-defensive actions and children must not have been present at the homicide, both elements definitely raising the likelihood of prosecution. But, any suggestion that her actions were in the defense of the children (either at the time of the killing or from the man's actions toward them in the past) seemed to render her quite blameless.

Other themes included: 1) If the woman historically had major life difficulties, irrespective of her relationship with the man she killed, she was more of a sympathetic character (i.e., mentally deficient, mentally disordered, abused as a child or previously as an adult); 2) If the woman discovered her husband in the act of infidelity, participants were less likely to prosecute; and 3) the impact of such a case upon the "community" might influence a decision to prosecute, such as the cost of a trial, a prosecutor's caseload, or concern about community backlash. These themes alert us to the potential problem of the intrusion of unfair or irrelevant variables impacting decision-making processes that warrant further exploration within the justice system. 


\section{Impact of Manipulated Factors within Vignettes on Decisions to Prosecute}

The best statistical data resulted from comparison of case elements within the vignettes. As predicted, many $(67 \%)$ of both legal and supplemental comparisons demonstrated differences in decision makers' likelihood to prosecute. Variables that did not demonstrate statistical differences, especially some self-defense factors, may have been insignificant due to an artifact of the way they were written, thus warranting further investigation.

Most interestingly, a number of vignette comparisons clearly demonstrated that case elements were influential for predictions of prosecution that contradicted the stated intent of participants in the first methodological approach. That is, case elements which decision makers reported they would not consider when they read that factor on a list of case elements often demonstrated a significant impact when decision makers responded to contrasting vignettes representing those factors. For example, in the first methodology, participants rated "personal characteristics of the woman," "the opinion of the dead man's family as to whether they wish for the woman to be prosecuted," and "the involvement of an advocacy group in the case" as factors they would not be likely to consider in deciding to prosecute. However, in the vignette comparisons, the woman's reputation in the community (whether she was faithful or rumored to be having an affair; whether she was well liked or not) was highly influential for a decision to prosecute, as were the dead man's family's preference for her to be prosecuted, and whether an advocacy group was involved, highlighting a potential discrepancy between intentions and actual impact. Supporting the likelihood of extraneous variables influencing decisions to prosecute is the match between those factors that did influence decision makers' likelihood to prosecute with anecdotal literature warning that particular stereotypes or case discrepancies with self-defense criteria may influence outcomes (e.g., Gillespie 1989) or with factors previously identified through quasi-experimental research manipulating personal variables of battered women defendants as problematic variables for these cases (e.g., Follingstad et al. 1996). The fact that this study identified personal aspects of the battered woman (i.e., her size, her drinking, her reputation), or the preference of the deceased man's family, or the woman's demeanor after the killing as producing significantly different orientations toward prosecution strongly suggests the need for greater understanding of these discretionary decisions.

\section{Implications and Recommendations for Future Research}

The fact that the participants in this study were college educated and somewhat sophisticated regarding criminal legal issues due to their presence in a Criminal Law course suggests that the results may be highly pertinent to how decisions to prosecute may currently be made within the criminal justice system. However, law students have not yet joined the work force as decision-makers in the legal arena, so their judgments were made without having had experience with actual battered women or self-defense cases. Thus, it is important to know whether legal experience in general, or specific experience with battered women's cases in which claims of self-defense are made, would result in different outcomes than the findings of this exploratory study. Essentially, the question to be answered would be, "Does more knowledge and/or experience provide a greater buffer from considering extraneous supplemental variables?" A future research study comparing law students' typical approach to these cases with that of prosecutors' approach, however, must not predetermine the potential direction or valence if differences are identified, as selective perception may rigidify pre-existing views rather than additional legal experience moving prosecutors toward viewing cases on individual merits.

As mentioned earlier, prosecutors may not be the only legal personnel involved in making judgments as to whether battered women's homicide cases should be prosecuted. What is unknown is whether prosecutors, law enforcement officers, grand jury members, and even judges in particular communities or states reflect similar views toward battered women and their legal cases. There has been some sensitization for legal professionals regarding women's issues (e.g., rape cases, battered women), which if they were exposed to such training, might predict different approaches to battered women homicide cases from grand jury members and possibly law enforcement officers. Future research needs to employ the range of these methodologies with these various decisionmakers to determine whether prosecutors, law enforcement officers, grand jury members, and judges demonstrate similar patterns to each other for these cases. Such research should assess whether participants received any training in women's issues, whether they specifically received training regarding battered women, and the amount of training they have accumulated. These data would be necessary to use as covariates in research assessing decisions to prosecute using the types of methodologies employed in this study.

Making decisions to prosecute battered women is, admittedly, a complex process. An important step for this research in the future would entail determining how prosecution decisions are made when multiple factors are salient and which factors are most predictive of final decisions. Possibly vignette studies that reflect the complicated scenarios for battered women's legal cases that incorporate multiple factors regarding self-defense, guilt/innocence, the woman's battering history, and extraneous supplemental variables would be useful for identifying the most predictive factors.

Further research that studies the process of discretionary decision-making as applied to battered women's homicide 
cases is likely to raise awareness of the complexity of decisionmaking for these cases and encourage greater accountability for understanding the influences on these decisions. Certainly, if training in women's issues impacts decisions that prosecutors make regarding battered women's homicide cases, this finding would have implications for instituting and evaluating such training programs. Defense lawyers may need to be cognizant of research results of this type to pre-empt decision-making that might arise from stereotypical biases toward battered women. And, this line of research may also stimulate the investigation of other decisions to prosecute in the criminal justice system beyond these specific cases to illuminate and potentially impact this discretionary process.

\section{References}

Albonetti, C. A. (1986). Criminality, prosecutorial screening, and uncertainty: toward a theory of discretionary decision making in felony case processings. Criminology, 24(4), 623-644.

Albonetti, C. A., \& Hepburn, J. R. (1996). Prosecutorial discretion to defer criminalization: the effects of defendant's ascribed and achieved status characteristics. Journal of Quantitative Criminology, 12(1), 63-81.

Allen, J. G., Scovern, A. W., Logue, A. M., \& Coyne, L. (1988). Indications for extended psychiatric hospitalization: a study of clinical opinion. Comprehensive Psychiatry, 29(6), 604-612.

Banaji, M. R., \& Hardin, C. D. (1996). Automatic stereotyping. Psychological Science, 7(3), 136-141. doi:10.1111/j.1467-9280. 1996.tb00346.x.

Blackman, J. (1990). Emerging images of severely battered women and the criminal justice system. Behavioral Sciences \& the Law, 8(2), 121-130.

Braden-Maguire, J., Sigal, J., \& Perrino, C. S. (2005). Battered women who kill: variables affecting simulated jurors' verdicts. Journal of Family Violence, 20(6), 403-408. doi:10.1007/s10896-005-7801-0.

Brewer, M. B. (1996). When stereotypes lead to stereotyping: The use of stereotypes in person perception. In C. N. Macrae, C. Stangor, \& M. Hewstone (Eds.), Stereotypes and stereotyping. New York: Guilford Press.

Browne, A., \& Williams, K. R. (1989). Exploring the effect of resource availability and the likelihood of female-perpetrated homicides. Law and Society Review, 23(1), 75-94.

Cheyne, N., \& Dennison, S. (2005). An examination of a potential reform to the provocation defence: the impact of gender of the defendant and the suddenness requirement. Psychiatry, Psychology and Law, 12(2), 388-400. doi:10.1375/pplt.12.2.388.

Cohen, T. H., \& Kyckelhahn, T. (2010). Felony defendants in large urban counties, 2006. BOJ Statistics.

Devine, P. G. (1989). Stereotypes and prejudice: their automatic and controlled components. Journal of Personality and Social Psychology, 56(1), 5-18. doi:10.1037/0022-3514.56.1.5.

Ewing, C. P., \& Aubrey, M. (1987). Battered woman and public opinion: some realities about the myths. Journal of Family Violence, 2(3), 257-264. doi:10.1007/bf00976543.

Fairfax, R. (2008). Grand jury discretion and constitutional design. Cornell Law Review, 93(4), 703-764.

Finkel, N. J., Meister, K. H., \& Lightfoot, D. M. (1991). The self-defense defense and community sentiment. Law and Human Behavior, 15(6), 585-602. doi:10.1007/bf01065854.
Follingstad, D. R. (1996). Forensic evaluations of battered women defendants: relevant data to be applied to elements of self-defense. Applied and Preventive Psychology, 5, 165-178.

Follingstad, D. R. (2003). Battered woman syndrome in the courts: Issues and application. In A. Goldstein (Ed.), Handbook of psychology: Volume 11 - forensic psychology (pp. 485-507). Hoboken: Wiley.

Follingstad, D. R., Neckerman, A., \& Vormbrock, J. (1988). Reactions to victimization and coping strategies of battered women: the ties that bind. Clinical Psychology Review, 8, 1-18.

Follingstad, D. R., Polek, D. S., Hause, E. S., Deaton, L. H., Bulger, M. W., \& Conway, Z. D. (1989). Factors predicting verdicts in cases where battered women kill their husbands. Law and Human Behavior, 13, 253-269.

Follingstad, D. R., Rutledge, L. L., Berg, B. J., Hause, E. S., \& Polek, D. S. (1990). The role of emotional abuse in physically abusive relationships. Journal of Family Violence, 5, 107-120.

Follingstad, D. R., Brondino, M. J., \& Kleinfelter, K. J. (1996). Reputation and behavior of battered women who kill their partners: do these variables negate self-defense? Journal of Family Violence, $11,251-267$.

Follingstad, D. R., Shillinglaw, R. D., DeHart, D. D., \& Kleinfelter, K. J. (1997). The impact of elements of self-defense and objective versus subjective instructions on jurors' verdicts for battered women defendants. Journal of Interpersonal Violence, 12(5), 729-747.

Follingstad, D. R., Runge, M. M., Ace, A., Buzan, R., \& Helff, C. (2001). Justifiability, sympathy level, and internal/external locus of the reasons battered women remain in abusive relationships. Violence and Victims, 16(6), 621-644.

Gawronski, B., Hofmann, W., \& Wilbur, C. J. (2006). Are 'implicit' attitudes unconscious? Consciousness and Cognition An International Journal, 15(3), 485-499. doi:10.1016/j.concog.2005. 11.007 .

Gigerenzer, G., Todd, P. M., \& The ABC Research Group. (1999). Simple heuristics that make us smart. New York: Oxford University Press.

Gillespie, C. K. (1989). Justifiable homicide. Columbus: Ohio State University Press.

Goetting, A. (1987). Homicidal wives: a profile. Journal of Family Issues, 8(3), 332-341.

Goldstein, D. G., \& Gigerenzer, G. (2002). Models of ecological rationality: the recognition heuristic. Psychological Review, 109(1), 7591.

Greenwald, A. G., \& Banaji, M. R. (1995). Implicit social cognition: attitudes, self-esteem, and stereotypes. Psychological Review, 102(1), 4-27. doi:10.1037/0033-295x.102.1.4.

Jenkins, P., \& Davidson, B. (1990). Battered women in the criminal justice system: an analysis of gender stereotypes. Behavioral Sciences \& the Law, 8, 161-170.

Kahan, D. M., \& Braman, D. (2008). The self-defensive cognition of selfdefense. American Criminal Law Review, 45, 1-46.

Kalven, H. (1969). Study of the California penalty jury in first degree murder cases. Stanford Law Review, 21(6), 1297-1497.

Kuhl, A. F. (1984). Personality traits of abused women: masochism myth refuted. Victimology, 9(3-4), 450-463.

McClelland, D. C., Koestner, R., \& Weinberger, J. (1989). How do selfattributed and implicit motives differ? Psychological Review, 96(4), 690-702.

Myers, D. G. (2002). Social psychology. Boston: McGraw-Hill Higher Education.

Myers, M. A., \& Hagan, J. (1979). Private and public trouble: prosecutors and the allocation of court resources. Social Problems, 26(4), 439451.

Narby, D. J., Cutler, B. L., \& Moran, G. (1993). A meta-analysis of the association between authoritarianism and jurors' perceptions of defendant culpability. Journal of Applied Psychology, 78(1), 34-42. 
O’Neill, M. E. (2004). Understanding federal prosecutorial declinations: an empirical analysis of predictive factors. American Criminal Law Review, 41, 1439-1498.

Parrotta, K. L. (2006). Disparity in prosecutorial decision-making in North Carolina: The effects of processual factors. Unpublished Master's thesis. Raleigh, NC: North Carolina State University.

Pate, K. (1994). Battered women's defence committee update. www. elizabethfry.ca/bwdcom.htm.

Pennington, N., \& Hastie, R. (1992). Explaining the evidence: tests of the story model for juror decision making. Journal of Personality and Social Psychology, 62(2), 189-206. doi:10.1037/0022-3514.62.2. 189.

Piperides, C., Allen, R. J., Dhami, M. K., Flessner, A., Hastie, R., Koehler, J. J., Lempert, R., Schulz, J., \& Wagner, G. (2006). Group report: What is the role of heuristics in litigation? In G. Gigerenzer \& C. Engel (Eds.), Heuristics and the law (pp. 343377). Cambridge: MIT Press.

Radelet, M. L., \& Pierce, G. L. (1985). Race and prosecutorial discretion in homicide cases. Law and Society Review, 19(4), 587-621.

Roberts, A. R. (1996). Battered women who kill: a comparative study of incarcerated participants with a community sample of battered women. Journal of Family Violence, 11(3), 291-304.

Russell, B. L., \& Melillo, L. S. (2006). Attitudes toward battered women who kill: defendant typicality and judgments of culpability. Criminal Justice and Behavior, 33(2), 219-241.
Schneider, E. M., \& Jordan, S. B. (1978). Representation of women who defend themselves in response to physical or sexual assault. American Journal of Trial Advocacy, 1(19), 19-46.

Schuller, R. A., Smith, V. L., \& Olson, J. M. (1994). Jurors' decisions in trials of battered women who kill: the role of prior beliefs and expert testimony. Journal of Applied Social Psychology, 24(4), 316-337.

Schuller, R. A., Wells, E., Rzepa, S., \& Klippenstine, M. A. (2004). Rethinking battered woman syndrome evidence: the impact of alternative forms of expert testimony on mock jurors' decisions. Canadian Journal of Behavioural Science, 36(2), 127-136. doi: 10.1037/h0087223.

Shaver, K., Gilbert, M., \& Williams, M. (1975). Social psychology, criminal justice, and the principle of discretion: a selective review. Personality and Social Psychology Bulletin, 1(3), 471-484.

Smith, V. (1991). Prototypes in the courtroom: lay representation of legal concepts. Journal of Personality and Social Psychology, 61, 857872.

Snell, J. E., Rosenwald, R. J., \& Robey, A. (1964). The wifebeater's wife. Archives of General Psychiatry, 11(2), 107-112.

Terrance, C. A., Matheson, K., \& Spanos, N. P. (2000). Effects of judicial instructions and case characteristics in a mock jury trial of battered women who kill. Law and Human Behavior, 24(2), 207-229. doi: 10.1023/a:1005411003414.

Wilbanks, W. (1983). The female homicide offender in Dade, county, Florida. Criminal Justice Review, 8(2), 9-14. 